\title{
Kail sawdust charcoal: a low-cost adsorbent for removal of textile dyes from aqueous solution
}

\author{
Vandana Gupta ${ }^{1} \cdot$ Anupam Agarwal $^{2} \cdot$ M. K. Singh ${ }^{3} \cdot$ N. B. Singh ${ }^{2,4}$
}

(C) Springer Nature Switzerland AG 2019

\begin{abstract}
Kail sawdust charcoal was used as an adsorbent for the removal of Torque blue, red RB and yellow M4G (textile dyes) dyes from aqueous solution. Adsorption was carried out at different concentrations of dye solution, dose of adsorbent, temperature, $\mathrm{pH}$ and particle size. The adsorption data were best fitted by Langmuir adsorption isotherm and pseudosecond-order kinetic models. Thermodynamic parameters $\left(\Delta G^{\circ}, \Delta H^{\circ}\right.$ and $\left.\Delta S^{\circ}\right)$ were determined, and the results indicated that adsorption was spontaneous, feasible and exothermic. Adsorption was better at higher $\mathrm{pH}$ for torque blue and at lower $\mathrm{pH}$ for red RB and Yellow M4G dyes. Kail sawdust charcoal (bio waste) would be quite effective and economical adsorbent for the treatment of textile dye wastewater.
\end{abstract}

Keywords Adsorption · Kail sawdust charcoal · Torque blue · Red RB · Yellow M4G

\section{Introduction}

Nowadays, textile industries are emerging as the most polluting industry worldwide. These industries release dyes and other chemicals, e.g., caustic soda, formic acid, organic resins, soap, softener, wetting agent, etc., into the environment which are harmful [1]. The dye is harmful as it may cause eye irritation, skin irritation and digestive tract irritation, if inhaled [2]. In aerobic conditions, it is considered mutagenic to living organisms. The treatment of textile effluents is becoming the most challenging task. In the past few years, several techniques have been adopted for removal of textile dyes from aqueous solution but adsorption method is found to be more convenient, efficient and economical [3]. Singh et al. [3] discussed in detail the use of different types of adsorbents for water purification. However, activated carbon is one of the oldest and widely used adsorbents. It is generally obtained from coal and is very costly. Due to economic reasons, agricultural materials are the most preferred choice as the substitute of activated carbon. The basic requirement for activated carbon is that it should have porous structure with pores of different sizes. However, pore sizes depend on the source material and method of preparation. By now, many agricultural and low-cost materials have been reported for dye removal from aqueous solution [4-6].

Raw agrowastes in general have low adsorption capacity, and soluble organic matters go into solution, tending to increase its total organic carbon (TOC), and chemical/ biological oxygen demands. The efficiency of adsorption by agricultural residues can be enhanced by chemical modifications [7]. Recently, activated carbons derived from various carbonaceous materials such as cocoa shell, coconut shell $\left(\mathrm{H}_{3} \mathrm{PO}_{4}\right)$, pineapple waste $\left(\mathrm{ZnCl}_{2}\right)$, sour cherry stones $\left(\mathrm{ZnCl}_{2}\right)$, coconut shell $(\mathrm{KOH})$, Cucumis sativus $\left(\mathrm{H}_{2} \mathrm{SO}_{4}\right)$, olive-waste cake $\left(\mathrm{H}_{3} \mathrm{PO}_{4}\right)$, Kenaf core fiber $\left(\mathrm{H}_{3} \mathrm{PO}_{4}\right)$, date stone $\left(\mathrm{FeCl}_{2} / \mathrm{ZnCl}_{2}\right)$, sugarcane bagasse $(\mathrm{KOH})$, orange peel $\left(\mathrm{K}_{2} \mathrm{CO}_{3}\right)$ and linseed deoiled cake $\left(\mathrm{H}_{3} \mathrm{PO}_{4}\right)$ have been

$\triangle$ N. B. Singh, nbsingh43@gmail.com | 1 Department of Applied Science, Aryan Institute of Technology, Ghaziabad, India. ${ }^{2}$ Department of Chemistry and Biochemistry, School of Basic Sciences and Research, Sharda University, Greater Noida, India. ${ }^{3}$ Department of Science and Humanities, Institute of Management and Research, Ghaziabad, India. ${ }^{4}$ Research and Technology Development Centre, Sharda University, Greater Noida, India.

SN Applied Sciences (2019) 1:1271 | https://doi.org/10.1007/s42452-019-1252-3 
prepared by chemical activation for treatment of industrial wastewater [2].

Although the adsorption capacities of the above materials are very high, most of them have been used either for non-textile dyes or for those dyes which are currently not in use. So some new adsorbents, which can easily be available and have high potential for removal of currently used textile dyes, are found out.

The waste product obtained from carpenter shop (Kail sawdust) is available in plenty and can be converted to carbon, which can be used as an adsorbent for removal of dyes from water. In this paper, Kail sawdust was converted into charcoal (KSC) by carbonization and has been used as adsorbent for removal of torque blue, red RB and yellow M4G dyes from aqueous solution. These dyes are generally used for dyeing cotton, rayon, silk, wool and nylon fabrics. Torque blue is cationic (oxazine class) dye. This class of dye is very toxic to aquatic life and may cause eye irritation, vomiting, jaundice, tissue necrosis, cyanosis, shock, bladder cancer, etc. in human beings [8, 9]. Red RB and Yellow M4G are anionic (single azo) dyes. The degradation products of azo dyes such as aniline, toluene, benzidine and naphthalene have been reported to be allergenic, mutagenic, teratogenic and carcinogenic in the literature [10]. Effects of various parameters such as contact time, initial dye concentration, particle size of adsorbent, adsorbent dosage, $\mathrm{pH}$ and temperature have been studied for the removal of dyes by KSC. Different adsorption isotherms and kinetic models were tested, and the thermodynamic parameters were calculated.

\section{Materials and methods}

\subsection{Materials}

The Kail sawdust, obtained from the furniture market of Ghaziabad, India, was used as precursor for the synthesis of charcoal. The textile dyes, namely Torque blue, red RB and yellow M4G, were obtained from Rituraj Textile Industry, Mohan Nagar, Ghaziabad (UP), India.

\subsection{Methods}

\subsubsection{Preparation of adsorbent}

The Kail sawdust was soaked in distilled water for 2 days to remove all the impurities and color, present on the surface of sawdust and filtered. The filtered sawdust was dipped in dilute $\mathrm{HCl}$ to dissolve the remaining impurities. It was then filtered and dried in sunlight for 5-6 $d$ and then in an oven for $15 \mathrm{~h}$ at $120^{\circ} \mathrm{C}$. The dried sawdust was ground by mechanical grinder into fine powder and then placed in a muffle furnace at $400{ }^{\circ} \mathrm{C}$ for half an hour. After the carbonization, the sawdust was taken out from muffle furnace, cooled, washed and dried. Finally, this wood charcoal was divided into four ranges of particle sizes by sieving and getting particle size of 75-149 $\mu \mathrm{m}$, 150-299 $\mu \mathrm{m}, 300-599 \mu \mathrm{m}$ and 600-899 $\mu \mathrm{m}$, and after that, the surface areas were determined. The obtained KSC was then kept in an airtight closed bottle and was used as an adsorbent.

\subsubsection{BET surface area}

BET surface area of KSC was measured $(10.762,5.381$, 2.691 and $1.6143 \mathrm{~m}^{2} / \mathrm{g}$ ) using liquid nitrogen by Quantachrome Instruments version 5.0 at Banasthali Vidhyapith, Jaipur.

\subsubsection{Preparation of adsorbates}

The stock solutions of $50 \mathrm{mg} / 100 \mathrm{~mL}$ of torque blue, red RB and yellow M4G dyes were prepared by dissolving predetermined, accurately weighed amount of dyes in doubledistilled water, and experimental solutions were prepared by suitable dilution of stock solutions. The chemical structures of different dyes are given in Fig. 1a-c.

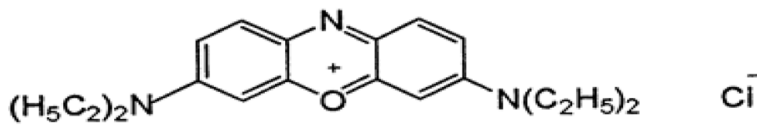

a Chemical structure of Torque Blue

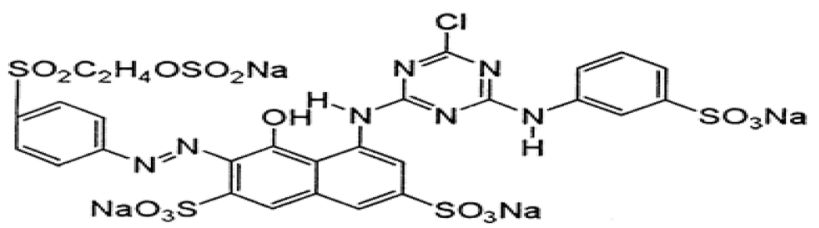

b Chemical structure of Red RB<smiles>COc1ccc(S(=O)(=O)OCCOS(=O)(=O)O[Na])cc1N/N=C1\C(=O)N(c2c(C)cc(S(=O)(=O)O[Na])cc2Cl)N=C1C</smiles>

c Chemical structure of Yellow M4G

Fig. 1 a Chemical structure of torque blue, $\mathbf{b}$ chemical structure of red $\mathrm{RB}$ and $\mathbf{c}$ chemical structure of yellow M4G 


\subsubsection{SEM studies}

The surface morphology of Kail sawdust, Kail sawdust charcoal and Kail sawdust charcoal after torque blue dye adsorption were examined with SEM model No Zeiss 18 EVO.

\subsubsection{Spectral studies}

FTIR spectra of KSC before and after adsorption of torque blue, red RB and yellow M4G dyes were recorded with Cary $630 \mathrm{FTIR}$

\subsubsection{Determination of zero point charge $\left(\mathrm{pH}_{\mathrm{zpc}}\right)$}

To determine the point of zero charge $\left(\mathrm{pH}_{\mathrm{zpc}}\right)$ or the $\mathrm{pH}$ value at which the surface charge of $\mathrm{KSC}$ is zero, $50 \mathrm{~mL}$ $0.01 \mathrm{M}$ solution of $\mathrm{NaCl}$ was taken and the $\mathrm{pH}$ of the solution was made 2 by adding $\mathrm{HCl} / \mathrm{NaOH}$. In a similar way, $\mathrm{NaCl}$ solution in five separate conical flasks was taken and the $\mathrm{pH}\left(\mathrm{pH}_{\mathrm{i}}\right)$ was maintained to $3,4,5,6,7,8,9$ and 10 . $0.20 \mathrm{~g}$ of KSC was added to each flask and left at room temperature for $48 \mathrm{~h}$. When the $\mathrm{pHs}$ were stabilized, the solutions were filtered and the final $\mathrm{pHs}\left(\mathrm{pH}_{\mathrm{f}}\right)$ were measured. A graph was plotted between $\Delta \mathrm{pH}\left(\mathrm{pH}_{\mathrm{i}}-\mathrm{pH}_{\mathrm{f}}\right)$ and initial $\mathrm{pHs}\left(\mathrm{pH}_{\mathrm{i}}\right)$. The point of intersection is the $\mathrm{pH}_{\mathrm{zpc}}$ of the KSC. It was found to be 5.8 (Fig. 2).

\subsubsection{Batch experiment for removal of dyes}

Batch experiments were carried out by stirring $0.3-0.7 \mathrm{~g}$ of the KSC (adsorbent) in rotatory shaker with $100 \mathrm{~mL}$ aqueous solution of dyes having concentration $10-30 \mathrm{mg} / \mathrm{L}$. KSC (surface area $5.381 \mathrm{~m}^{2} / \mathrm{g}$ ) was mixed with dye solutions. However, experiments with KSC of different surface areas were also conducted to see the effect of surface area on adsorption. All experiments were carried out by changing the temperature and $\mathrm{pH}$ of solutions from 300 to $330 \mathrm{~K}$ and 3.0-9.0, respectively. The temperature was maintained within $\pm 1{ }^{\circ} \mathrm{C}$ for a prescribed period of time to attain

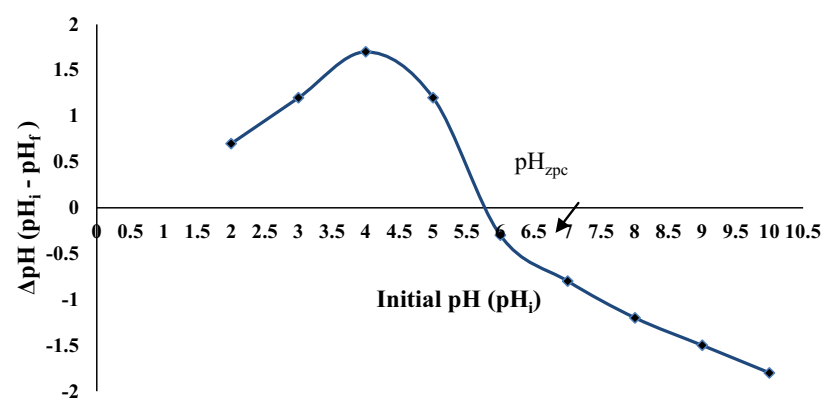

Fig. 2 Determination of $\mathrm{pH}_{\mathrm{zpc}}$ equilibrium. The required $\mathrm{pH}$ of the solution was adjusted by adding calculated amount of $0.1 \mathrm{~N} \mathrm{HCl} / \mathrm{NaOH}$. The duration of each batch experiment was about 90 min. After every $15 \mathrm{~min}$, the solutions were filtered through Whatman filter paper and concentrations of dyes in the solutions were determined by measuring the absorbance at a wavelength corresponding to their maximum absorbance (667, 528 and $390 \mathrm{~nm}$ for TB, RRB and YMG, respectively) with the help of Shimadzu UV-1800 spectrophotometer.

Calibration curves for each dye were plotted.

The amount of dyes adsorbed onto KSC and percentage removal of dye were calculated by using Eqs. 1 and 2 .

$q_{\mathrm{e}}=\left(\frac{C_{\mathrm{o}}-C_{\mathrm{e}}}{M}\right) * V$

$\%$ Dye removal $=\left(\frac{C_{\mathrm{o}}-C_{\mathrm{e}}}{C_{\mathrm{o}}}\right) * 100$

where $q_{\mathrm{e}}$ is the amount of dye adsorbed at equilibrium, $C_{\mathrm{o}}$ is the initial concentration of dye in the solution, $C_{e}$ is the final concentration of dye at equilibrium, $M$ is the mass of adsorbent $(g)$ and $V$ is the volume of solution (L).

\section{Results}

\subsection{Characterization of adsorbent}

\subsubsection{SEM studies}

SEM pictures of Kail sawdust (Fig. 3a, b) show that the adsorbent surface has very rough and porous texture. It is clearly visible from the images that size of pores is between $2.1 \mu \mathrm{m}$ and $3.3 \mu \mathrm{m}$.

The micrographs of Kail sawdust Charcoal (KSC) are shown in Fig. $4 a$, b; which reveal that roughness and porosity on adsorbent surface have been increased by carbonization, which would definitely enlarge surface area as compared to non-carbonized adsorbents for adsorption. Size of pores is between $4.9 \mu \mathrm{m}$ and $6.8 \mu \mathrm{m}$.

SEM images of Kail sawdust charcoal after torque blue dye adsorption are shown in Fig. 5a, b. These micrographs show that the surface of KSC is slightly smoothened by dye adsorption, indicating the adsorption of dye.

\subsubsection{FTIR spectral studies}

FTIR spectra of KSC before adsorption and after adsorption of torque blue, red RB and yellow M4G are shown in Fig. 6 . The bands appearing in anhydrous KSC at $1610 \mathrm{~cm}^{-1}, 1590 \mathrm{~cm}^{-1}$ may be due to amide $(\mathrm{N}-\mathrm{H})$ groups in sawdust [11]. The band at $1215 \mathrm{~cm}^{-1}$ shows the 

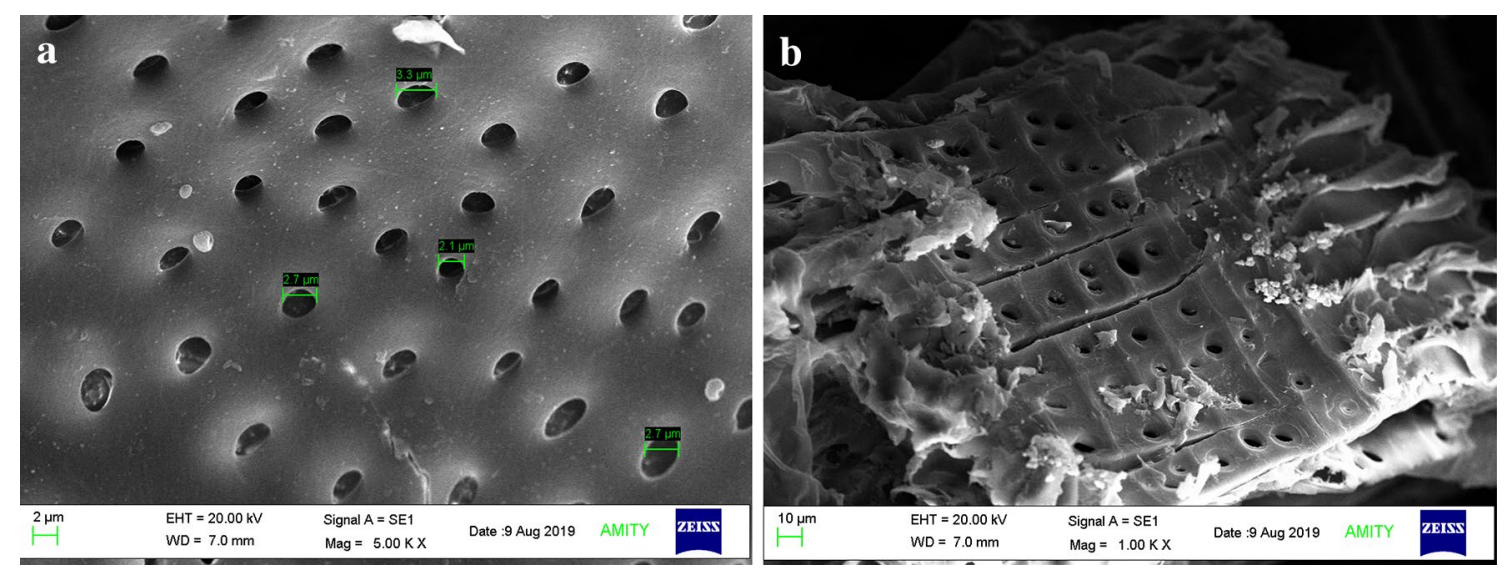

Fig. 3 a, b SEM images of Kail sawdust (KS) before carbonization
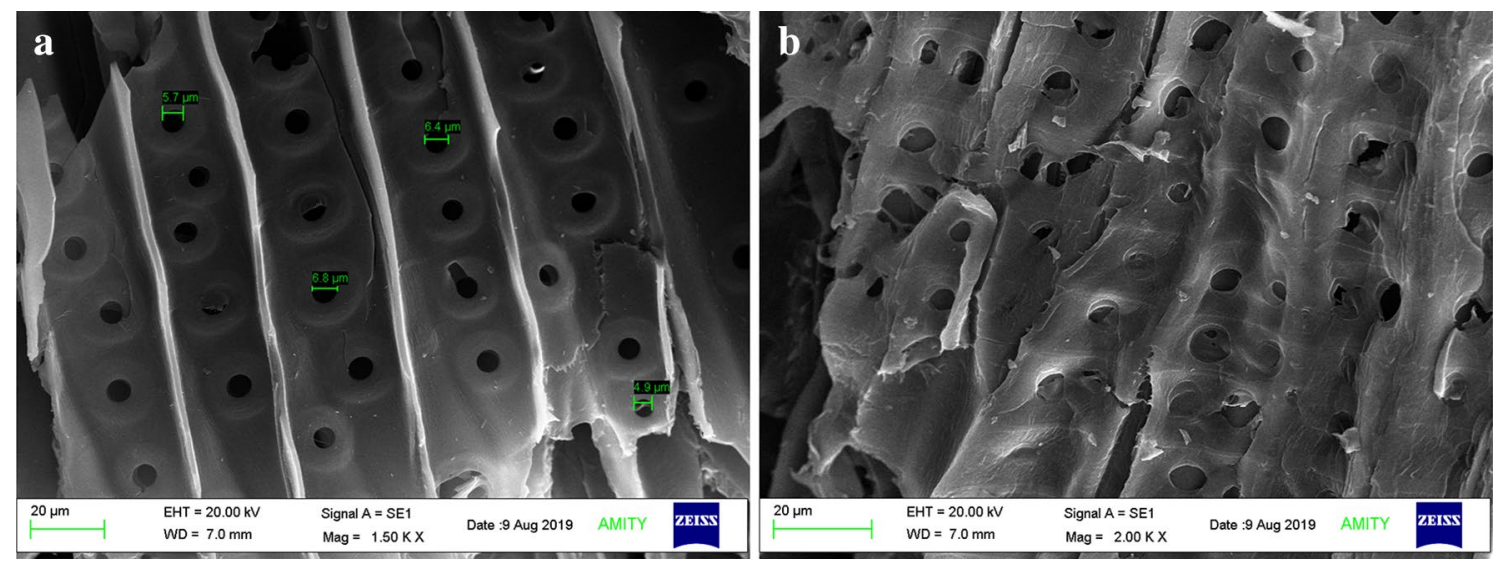

Fig. 4 a, b SEM images of Kail sawdust (KS) after carbonization
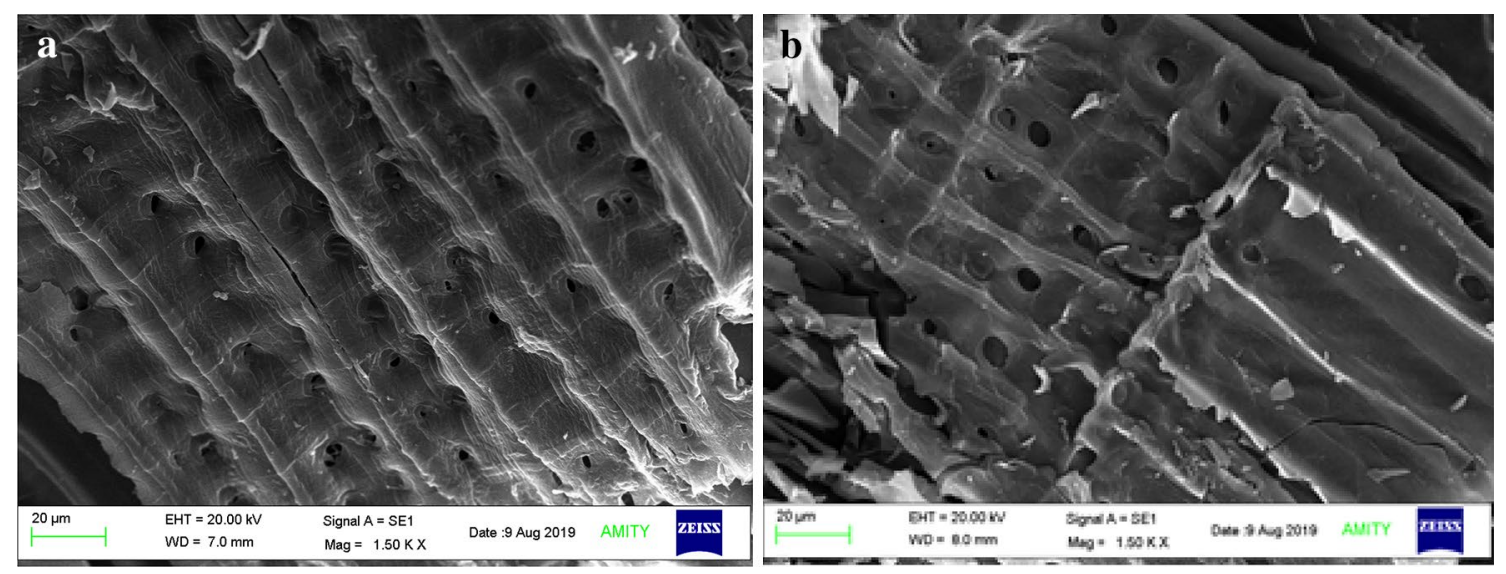

Fig. 5 a, b SEM images of Kail sawdust charcoal (KSC) after torque blue dye adsorption 


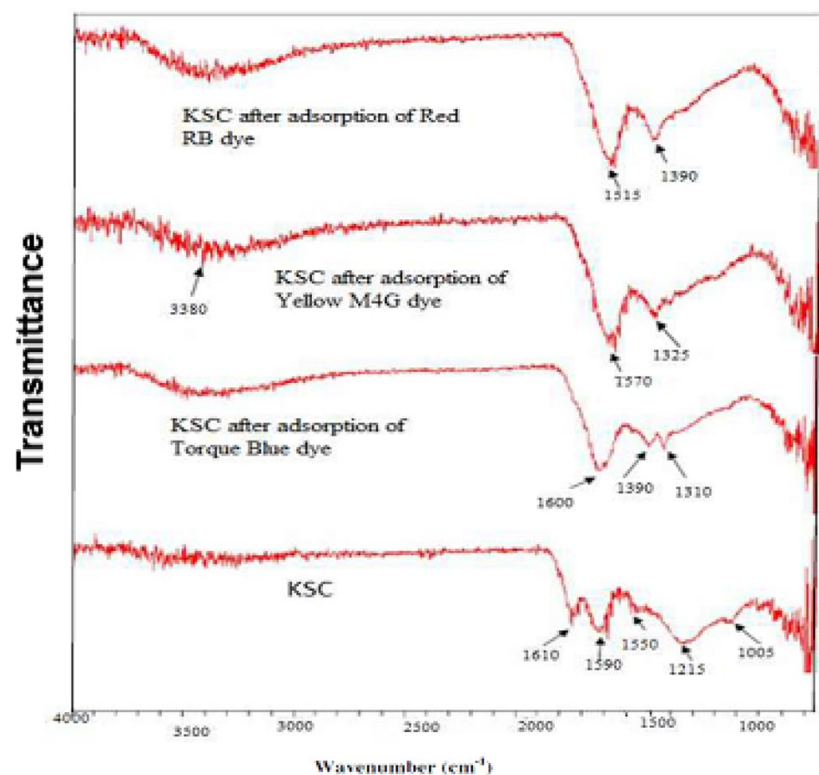

Fig. 6 FTIR spectra of KSC before and after adsorption of torque blue, red RB and yellow M4G dyes

crystalline cellulose, and the band at $1005 \mathrm{~cm}^{-1}$ shows $\mathrm{C}-\mathrm{O}-\mathrm{C}$ symmetric stretching. The FTIR spectra of Kail sawdust charcoal after adsorption of dyes show shifting of bands and appearance of new bands. This indicated some sort of weak interactions between dye molecules and the surface of KSC. A broad peak at about $3400 \mathrm{~cm}^{-1}$ after dye adsorption may be due to $\mathrm{OH}$ group coming from water solution of dye.

\subsection{Removal of torque blue, red RB and yellow M4G dyes from aqueous solution}

The removal of textile dyes torque blue, red RB and yellow M4G from aqueous solutions by Kail sawdust charcoal (Pinus wallichiana) was examined at different concentrations (10-30 $\mathrm{mg} / \mathrm{L}$ ) of dye solutions, surface areas of KSC, adsorbent doses (0.3-1.0 g), pH (3.0-9.0) and temperatures $(300-330 \mathrm{~K})$. The percentage removal of dye under different conditions is shown in Figs. 7, 8, 9, 10 and 11. Figure 7 shows that as the concentration of dye increased, percent removal is decreased. As the surface area increased, adsorption increased (Fig. 8). With the increase in adsorbent dose, percent removal increased (Fig. 9). Figure 10 shows that percent removal of red RB and yellow M4G dyes decreased with increase in $\mathrm{pH}$, whereas in the case of torque blue dye it increased with increase in $\mathrm{pH}$. Further with increase in temperature, the percent removal of dyes decreased (Fig. 11).

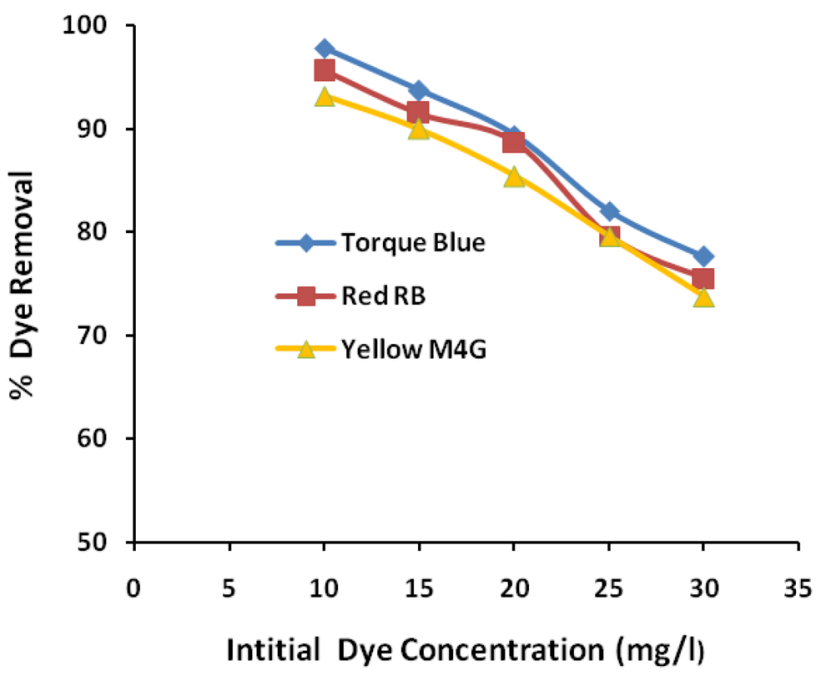

Fig. 7 Effect of initial dye concentration $10-30 \mathrm{mg} / \mathrm{L}$ ) on adsorption of dyes on KSC

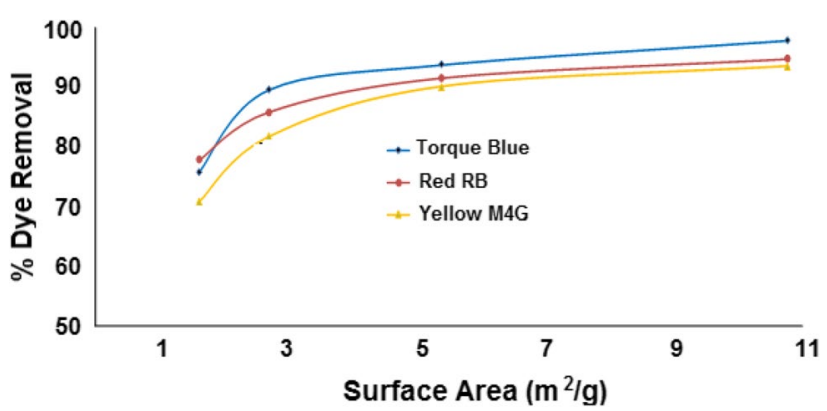

Fig. 8 Effect of surface area on adsorption of dyes on KSC

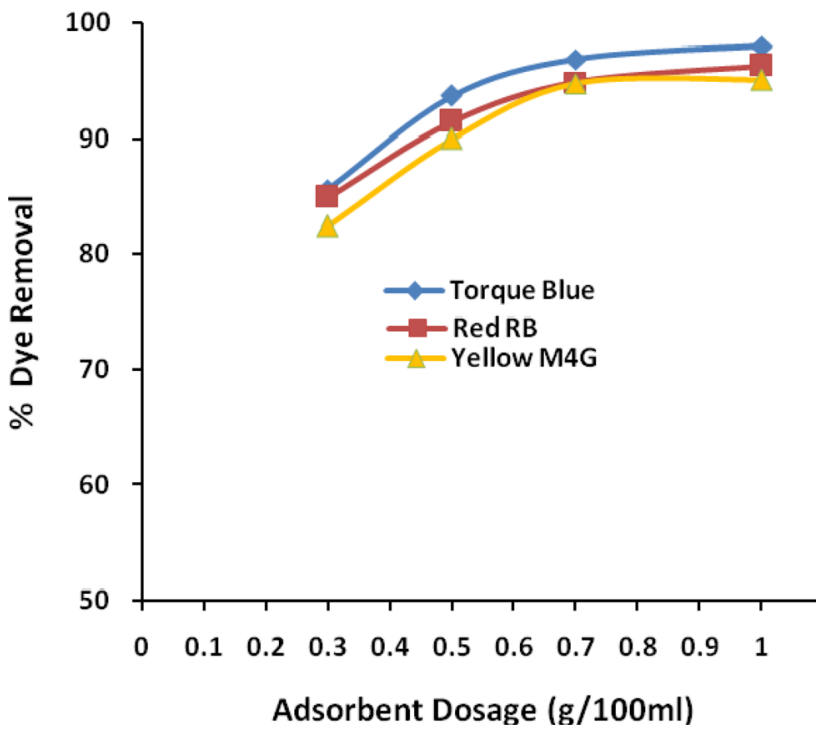

Fig. 9 Effect of adsorbent dosage (0.3-1.0 g) on adsorption of torque blue, red RB and yellow M4G dyes 


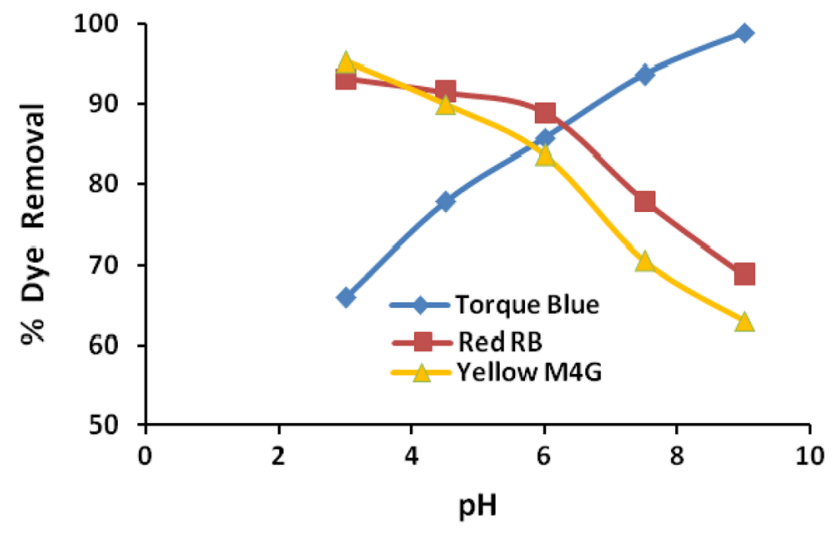

Fig. 10 Effect of $\mathrm{pH}(3.0-9.0)$ on adsorption of torque blue, red RB and yellow M4G dyes on KSC

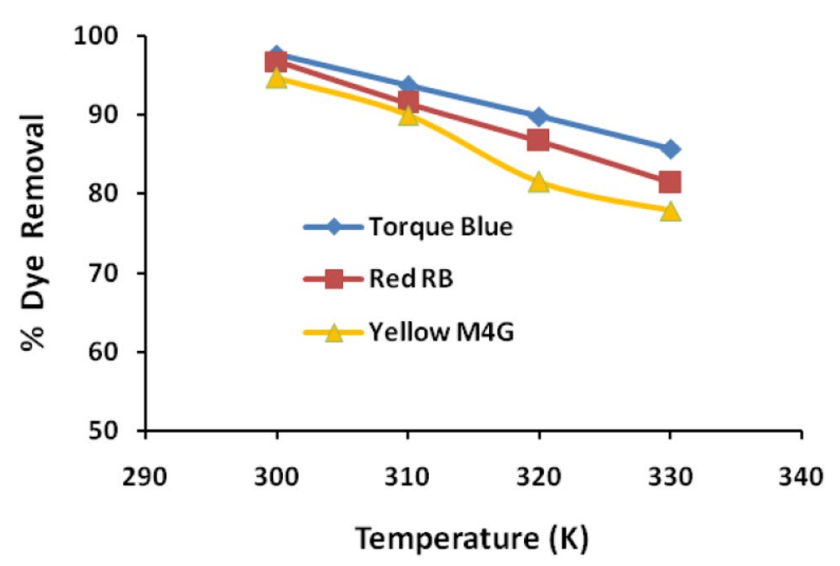

Fig. 11 Effect of temperature (300-330 K) on adsorption of torque blue, red RB and yellow M4G dyes on KSC

\subsection{Thermodynamic parameters}

Thermodynamic parameters, e.g., Gibbs free energy change $\left(\Delta G^{\circ}\right)$, enthalpy change $\left(\Delta H^{\circ}\right)$ and entropy change $\left(\Delta S^{\circ}\right)$, were estimated by using Eqs. 3-6.

$\Delta G^{\circ}=-R T \ln K$

where $R$ is the gas constant and $K$ is the equilibrium constant at temperature $T$.

The equilibrium constants $\left(K_{1}, K_{2}, K_{3}\right.$ and $\left.K_{4}\right)$ at temperatures $300,310,320$ and $330 \mathrm{~K}$ were calculated according to the relation:

$K_{\text {equ }}=\frac{C_{\text {ads }}}{C_{\text {sol }}}$

where $C_{\text {ads }}$ and $C_{\text {sol }}$ are the concentrations of dye on the adsorbent surface and in solution, respectively.

Entropy change $\left(\Delta S^{\circ}\right)$ is determined by Eq. 5 .

$\Delta S^{\circ}=\left[\frac{\Delta H^{\circ}-\Delta G^{\circ}}{T}\right]$

The enthalpy change $\left(\Delta \mathrm{H}^{\circ}\right)$ refers to the amount of energy released or absorbed in a chemical reaction, and it can be calculated by combining Eqs. 3 and 5:

$\ln K=\frac{\Delta S^{\circ}}{R}-\frac{\Delta H^{\circ}}{R T}$

Equation (6) is used to calculate the change in enthalpy $\left(\Delta H^{\circ}\right)$ and the change in entropy $\left(\Delta S^{\circ}\right)$ by plotting $\ln K$ versus $1000 / T$. The slopes and intercepts of the graphs were used to determine the values of $\Delta H^{\circ}$ and $\Delta S^{\circ}$, respectively. The calculated values of thermodynamic parameters are given in Table 1.
Table 1 Thermodynamic parameters of torque blue, red $\mathrm{RB}$ and yellow M4G dyes at different temperatures

\begin{tabular}{|c|c|c|c|c|c|}
\hline \multirow[t]{2}{*}{ Adsorbent } & \multirow[t]{2}{*}{ Dyes } & \multirow{2}{*}{$\begin{array}{l}\text { Tempera- } \\
\text { ture (K) }\end{array}$} & \multicolumn{3}{|l|}{ Parameters } \\
\hline & & & $-\Delta G^{\circ}(\mathrm{kJ} / \mathrm{mol})$ & $-\Delta H^{\circ}(\mathrm{kJ} / \mathrm{mol})$ & $-\Delta S^{\circ}(\mathrm{J} /(\mathrm{K} \mathrm{mol}))$ \\
\hline \multicolumn{6}{|c|}{ Thermodynamic parameters } \\
\hline \multirow[t]{12}{*}{ Kail sawdust charcoal } & Torque blue & 300 & 9.350 & 52.985 & 146.740 \\
\hline & & 310 & 6.957 & & \\
\hline & & 320 & 5.787 & & \\
\hline & & 330 & 4.912 & & \\
\hline & Red RB & 300 & 8.503 & 52.170 & 146.830 \\
\hline & & 310 & 6.124 & & \\
\hline & & 320 & 4.987 & & \\
\hline & & 330 & 4.049 & & \\
\hline & Yellow M4G & 300 & 7.190 & 46.176 & 130.450 \\
\hline & & 310 & 5.662 & & \\
\hline & & 320 & 3.945 & & \\
\hline & & 330 & 3.456 & & \\
\hline
\end{tabular}




\subsection{Adsorption isotherms}

The adsorption isotherms of torque blue, red RB and yellow M4G dyes at different concentrations were analyzed by applying Langmuir, Freundlich and Temkin adsorption isotherm models to understand the extent and degree of favorability of adsorption [3].

\subsubsection{Langmuir adsorption isotherm}

The basis of Langmuir equation is a saturated monolayer adsorption of adsorbate onto the homogeneous surface of adsorbent. It assumes that sorption energy remains constant during the process, and there is no transmigration of the

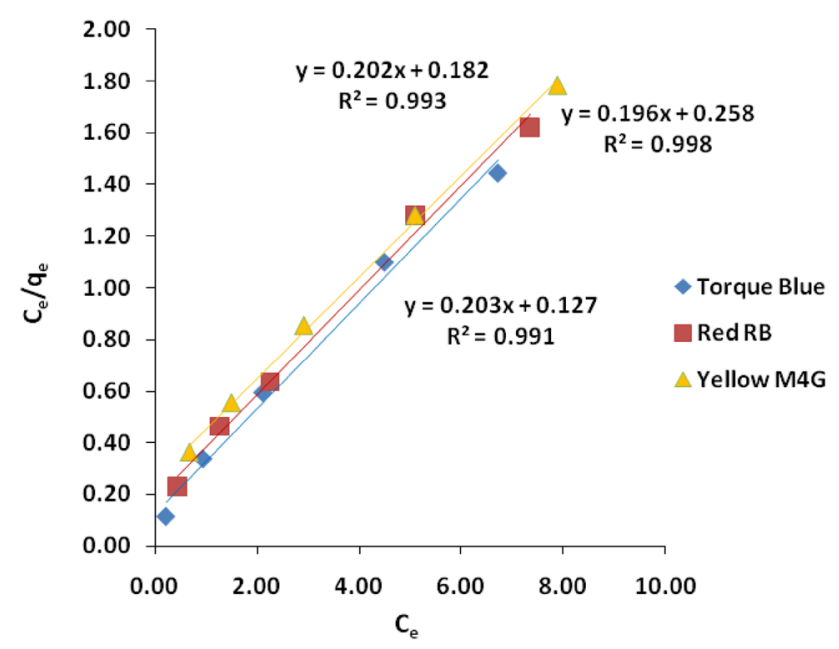

Fig. 12 Langmuir adsorption isotherm for torque blue, red RB and yellow M4G dyes adsorbate in the plane of surface. The Langmuir equation is given by Eq. 7 .

$\frac{C_{\mathrm{e}}}{q_{\mathrm{e}}}=\frac{1}{Q^{0} b}+\frac{C_{\mathrm{e}}}{Q^{0}}$

where $C_{e}$ is the remaining concentration of dye $(\mathrm{mg} / \mathrm{L})$ in solution at equilibrium; $q_{\mathrm{e}}$ is the amount of dye adsorbed at equilibrium $(\mathrm{mg} / \mathrm{g}) ; Q^{\circ}$ is the adsorption capacity of adsorbent, i.e., amount of dye adsorbed per unit weight of adsorbent in forming a complete monolayer on the surface $(\mathrm{mg} / \mathrm{g})$ and $\mathrm{b}(\mathrm{L} / \mathrm{mg})$ is the Langmuir constant related to energy of adsorption. The plots of $C_{\mathrm{e}} / q_{\mathrm{e}}$ versus $C_{e}$ (Fig. 12) for all the dyes gave straight lines over the entire concentration range studied with very high regression coefficients $(0.991-0.998)$. The values of $Q^{\circ}(\mathrm{mg} / \mathrm{g})$ and $b$ are calculated from the slope and intercept of the linear plots. The Langmuir parameters are given in Table 2. The results of Langmuir parameters showed that maximum adsorption capacity of KSC at $310 \mathrm{~K}$ was $5.102 \mathrm{mg} / \mathrm{g}$ for adsorption of Yellow M4G dye.

\subsubsection{Freundlich adsorption isotherm}

The Freundlich adsorption isotherm model was used to determine the adsorption intensity of the adsorbate onto the adsorbent surface [3]. It assumes non-ideal adsorption on the heterogeneous surface of adsorbent. The linearized equation of Freundlich isotherm model is given by Eq. 8 .

$\log q_{\mathrm{e}}=\log K_{\mathrm{f}}+\frac{1}{n} \log C_{\mathrm{e}}$

Table 2 Langmuir, Freundlich and Temkin adsorption constants of torque blue, red RB and yellow M4G dyes on KSC

\begin{tabular}{|c|c|c|c|c|}
\hline \multirow[t]{2}{*}{ Isotherms } & \multirow[t]{2}{*}{ Dyes } & \multicolumn{3}{|l|}{ Parameters } \\
\hline & & $Q^{\circ}(\mathrm{mg} / \mathrm{g})$ & $b(\mathrm{~L} / \mathrm{mg})$ & $R^{2}$ \\
\hline \multicolumn{5}{|c|}{ Adsorption isotherm constants } \\
\hline \multirow[t]{3}{*}{ Langmuir } & Torque blue & 4.926 & 1.598 & 0.991 \\
\hline & Red RB & 4.95 & 1.110 & 0.993 \\
\hline & Yellow M4G & 5.102 & 0.760 & 0.998 \\
\hline Isotherms & Dyes & $N$ & $K_{\mathrm{f}}(\mathrm{L} / \mathrm{mg})$ & $R^{2}$ \\
\hline \multirow[t]{3}{*}{ Freundlich } & Torque blue & 3.984 & 2.871 & 0.982 \\
\hline & Red RB & 3.333 & 2.535 & 0.978 \\
\hline & Yellow M4G & 2.857 & 2.239 & 0.996 \\
\hline Isotherms & Dyes & $B$ & $A(\mathrm{~L} / \mathrm{g})$ & $R^{2}$ \\
\hline \multirow[t]{3}{*}{ Temkin } & Torque blue & 0.775 & 49.116 & 0.984 \\
\hline & Red RB & 0.911 & 18.116 & 0.999 \\
\hline & Yellow M4G & 1.045 & 8.820 & 0.983 \\
\hline
\end{tabular}




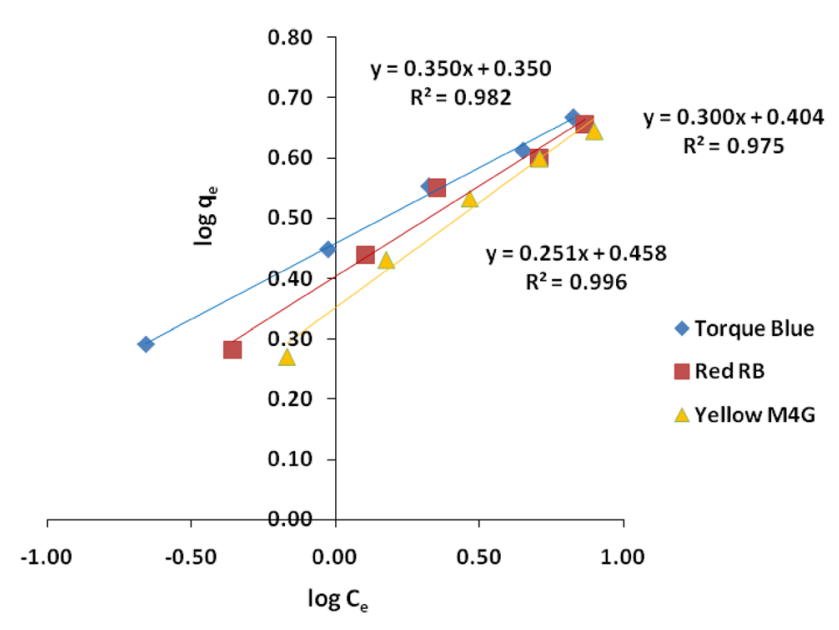

Fig. 13 Freundlich adsorption isotherm for torque blue, red RB and yellow M4G dyes

where $k_{\mathrm{f}}(\mathrm{L} / \mathrm{mg})$ is the adsorption or distribution coefficient, i.e., quantity of dye adsorbed onto adsorbent per unit equilibrium concentration [3] and $\mathrm{n}$ is the Freundlich constant related to adsorption intensity, which is used to know the deviation from linearity of adsorption. The Freundlich parameters calculated from the plots of $\log q_{\mathrm{e}}$ against $\log C_{e}$ (Fig. 13) are presented in Table 2. The values of $\mathrm{n}$ were found between 1 and 10, supporting that adsorption is favorable.

\subsubsection{Temkin adsorption isotherm}

The basis of Temkin isotherm model is adsorbate-adsorbent interaction on adsorption sites [3] and is given by Eq. 9.

$q_{\mathrm{e}}=B \ln A+B \ln C_{\mathrm{e}}$

where $B=\frac{R T}{b}, A(\mathrm{~L} / \mathrm{g})$ and $b(\mathrm{~J} / \mathrm{mol})$ are Temkin constants related to maximum binding energy and heat of sorption, respectively; $R$ is the gas constant $(8.314 \mathrm{~J} / \mathrm{mol} \mathrm{K})$, and $T$ is the absolute temperature (K). The plots of $q_{\mathrm{e}}$ against $\mathrm{In}$

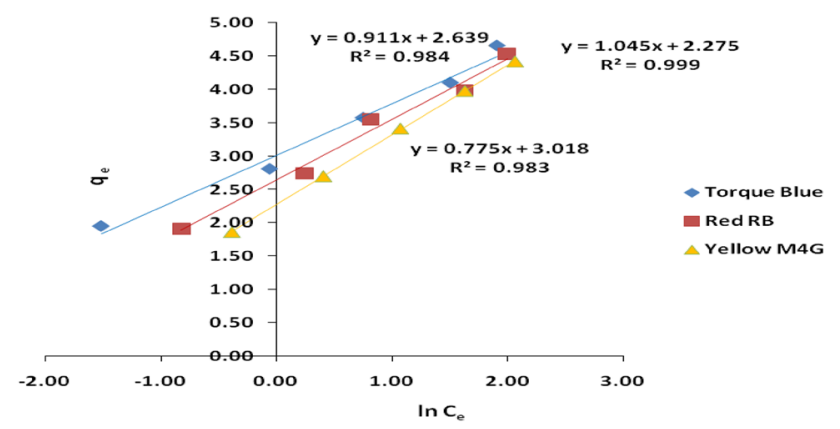

Fig. 14 Temkin adsorption isotherms for torque blue, red RB and yellow M4G dyes
$C_{\mathrm{e}}$ for various dyes are shown in Fig. 14, and the obtained parameters are given in Table 2.

\subsection{Kinetics of adsorption}

The kinetic studies of adsorption are important for the adsorbents in the dye removal from aqueous solution. Kinetic studies are helpful to describe the solute uptake rate by which the residence time of adsorption process can be determined. The efficiency of KSC for removal of dyes (torque blue, red RB and yellow M4G) at $310 \mathrm{~K}$ can be determined with the help of adsorption kinetics. To know the mechanism of adsorption phenomenon, the dynamical data were fitted into pseudo-first-order and pseudo-secondorder kinetic equations.

\subsubsection{Pseudo-first-order kinetics}

The pseudo-first-order kinetic model was applied for the adsorption of solid/liquid system. The integrated linear equation is given by Eq. 10 .

$\log \left(q_{\mathrm{e}}-q\right)=\log q_{\mathrm{e}}-\frac{k_{1}}{2.303} t$

where $q_{\mathrm{e}}$ and $q$ are the amounts of adsorbate $(\mathrm{mg} / \mathrm{g})$ at equilibrium and at any time $t$, respectively, and $k_{1}$ is the pseudo-first-order rate constant $\left(\mathrm{min}^{-1}\right)$. The plots of log $\left(q_{\mathrm{e}}-q\right)$ versus $\mathrm{t}$ for different dyes at temperature $310 \mathrm{~K}$ are depicted in Fig. 15. The values of $k_{1}$ and $q_{\mathrm{e}}$ were determined from the slopes and intercepts of the lines, and the values are given in Table 3.

\subsubsection{Pseudo-second-order kinetics}

The linear form of pseudo-second-order rate equation is expressed by Eq. 11 .

$\frac{t}{q}=\frac{1}{k_{2} q_{\mathrm{e}}^{2}}+\frac{t}{q_{\mathrm{e}}}$

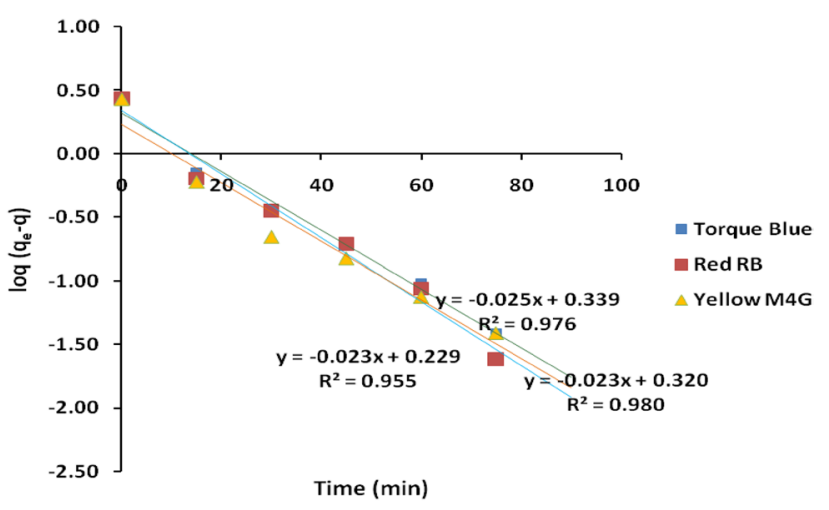

Fig. 15 Pseudo-first-order plots for the adsorption of torque blue, red RB and yellow M4G dyes on KSC 
Table 3 Kinetic parameters for adsorption of torque blue, red $\mathrm{RB}$ and yellow M4G dyes on KSC

\begin{tabular}{|c|c|c|c|c|c|c|c|}
\hline \multirow[t]{2}{*}{ Dyes } & \multicolumn{3}{|c|}{ Pseudo-first order } & \multicolumn{3}{|c|}{ Pseudo-second order } & \multirow{2}{*}{$\begin{array}{l}\text { Experi- } \\
\text { mental } q_{\mathrm{e}} \\
(\mathrm{mg} / \mathrm{g})\end{array}$} \\
\hline & $\begin{array}{l}\text { Calculated } \\
q_{\mathrm{e}}(\mathrm{mg} / \mathrm{g})\end{array}$ & $k_{1}\left(\min ^{-1}\right)$ & $R_{1}^{2}$ & $\begin{array}{l}\text { Calculated } \\
q_{\mathrm{e}}(\mathrm{mg} / \mathrm{g})\end{array}$ & $k_{2}(\mathrm{~g} / \mathrm{mg} / \mathrm{min})$ & $R^{2}$ & \\
\hline Torque blue & 2.089 & 0.053 & 0.980 & 2.882 & 0.100 & 0.996 & 2.811 \\
\hline Red RB & 2.183 & 0.058 & 0.976 & 2.817 & 0.106 & 0.996 & 2.750 \\
\hline Yellow M4G & 1.694 & 0.053 & 0.955 & 2.755 & 0.139 & 0.997 & 2.701 \\
\hline
\end{tabular}

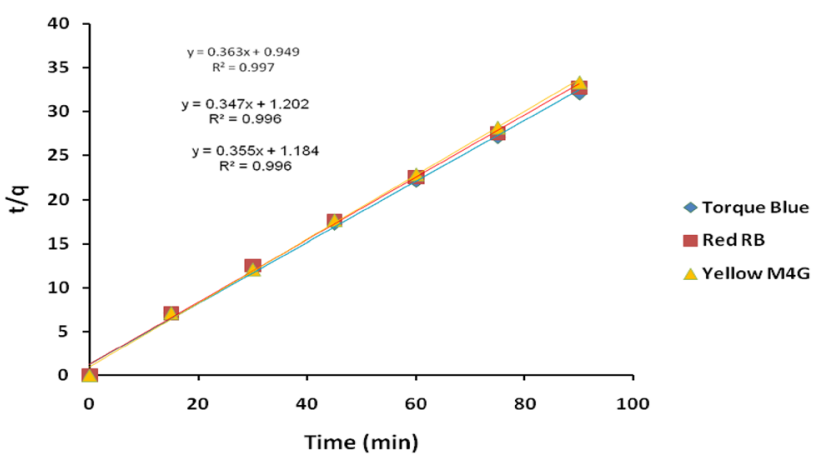

Fig. 16 Pseudo-second-order plots for the adsorption of torque blue, red RB and yellow M4G dyes on KSC

where $q_{\mathrm{e}}$ and $q$ are the amounts of adsorbate $(\mathrm{mg} / \mathrm{g})$ at equilibrium and at any time $t$, respectively, and $k_{2}$ is the pseudo-second-order rate constant ( $\mathrm{g} / \mathrm{mg} / \mathrm{min})$. The plots of $t / q$ versus $t$ for different dyes at temperature $310 \mathrm{~K}$ are presented in Fig. 16. The values of $k_{2}$ and $q_{\mathrm{e}}$ were calculated from the intercept and slope and are given in Table 3.

\section{Discussion}

Figure 7 shows that \% removal of torque blue by KSC decreased from 97.8 to $77.6 \%$, red RB from 95.6 to $75.5 \%$ and Yellow M4G from 93.2 to $73.7 \%$ with increase in initial dye concentration from 10 to $30 \mathrm{mg} / \mathrm{L}$. The optimum adsorption took place at $15 \mathrm{mg} / \mathrm{L}$. At higher concentrations of dye, the active adsorbent sites were insufficient for the same mass of the adsorbent, so adsorption decreased. This is similar to the adsorption of methylene blue and crystal violet on treated orange peel [12] and that of acridine orange and Azure B on activated carbon prepared from brown linseed deoiled cake [13].

The percent removal of dyes by KSC increased with surface area of KSC (Fig. 8). Maximum removal was in the case of torque blue dye.

As shown in Fig. 9, adsorption efficiency of KSC increased with increasing the quantity of adsorbent up to optimal amount beyond which adsorption attained equilibrium. At constant initial dye concentration, increasing the amount of adsorbent increased the number of unsaturated adsorbent sites, and as a consequence, more surface area was provided for adsorption [14]. The percent removal of torque blue increased from 85.6 to $98.0 \%$, red RB from 84.9 to $96.3 \%$ and Yellow M4G from 82.4 to $95.1 \%$, respectively, with increase in the amount of adsorbent from 0.3 to $1.0 \mathrm{~g}$. The optimum adsorption took place at adsorbent dosage of $0.5 \mathrm{~g}$.

The effect of $\mathrm{pH}$ was evaluated at varying $\mathrm{pH}$ from 3 to 9 (Fig. 10). At pH above $\mathrm{pH}_{\mathrm{zpc}}$ (5.8), surface attained a negative charge which favoured the adsorption of torque blue. The optimum value of $\mathrm{pH}$ for torque blue dye is 7.5. At $\mathrm{pH}$ below $\mathrm{pH}_{\mathrm{zpc}}$ (5.8), surface attained positive charge which favoured the adsorption of red RB and Yellow M4G. The optimum value of $\mathrm{pH}$ for red $\mathrm{RB}$ and Yellow M4G dyes is 4.0. It can be seen from Fig. 10 that on increasing the $\mathrm{pH}$ of solution from 3 to 9 , percentage removal for torque blue dye was increased from 65.8 to $98.9 \%$, while for red RB and Yellow M4G dyes it was decreased from 93.2 to $68.7 \%$ and 95.3 to $62.5 \%$, respectively. Each dye has different characteristics. Torque blue is a cationic dye, so its ions in the solution exist as positively charged species. Increase in the $\mathrm{pH}$ (above $\mathrm{pH}_{\mathrm{zpc}}$ ) of solution increased the negative charge on adsorbent surface. Subsequently, the negative adsorption sites were favorable for adsorption of cationic dye, but on the other hand, red RB and Yellow M4G dyes are anionic dyes, dispersed in solution as negatively charged species. On increasing the $\mathrm{pH}$, adsorbent surface also became negative which retarded the adsorption of negatively charged dye ions onto KSC due to electrostatic repulsion. Similar observations were reported in the literature for other anionic dyes [15].

The effect of temperature on percentage dye removal of torque blue, red RB and yellow M4g by KSC is shown in Fig. 11. It was observed that uptake capacity of KSC was decreased by increasing the temperature. This may occur due to the weakening of residual forces on the active sites of surface, so percent removal of torque blue decreased from 97.7 to $85.7 \%$, red RB from $96.8 \%$ to $81.4 \%$ and Yellow M4G from $94.7 \%$ to $77.9 \%$ with increase in temperature from $300 \mathrm{~K}$ to $330 \mathrm{~K}$. The optimum adsorption took place at a temperature of $310 \mathrm{~K}$. Similar results have already been reported [16].

The values of thermodynamic parameters $\left(\Delta G^{\circ}, \Delta H^{\circ}\right.$ and $\Delta S^{\circ}$ ) for torque blue, red RB and yellow M4G dyes at 
different temperatures are given in Table 1. The Gibbs free energy changes $\left(\Delta G^{\circ}\right)$ were found to be negative in all the cases, indicating that adsorption is spontaneous. The values of enthalpy changes $\left(\Delta H^{\circ}\right)$ were found negative for all the processes, suggesting exothermic nature of adsorption. Further the negative values of entropy changes $\left(\Delta S^{\circ}\right)$ indicated decreased disorder and randomness.

From Table 2, it can be concluded that Langmuir adsorption isotherm model fits the data better than Freundlich and Temkin adsorption isotherms models. The suitability of Langmuir model suggested the monolayer formation of dye molecules on the adsorbent surface.

Table 3 shows that the correlation coefficients for all the dyes by using pseudo-second-order kinetic model were very high (0.996-0.997). Furthermore, the theoretical $q_{\mathrm{e}}$ values were found very near to the experimental $q_{\mathrm{e}}$ values for second-order kinetics. Therefore, the adsorption kinetics was more dominated by pseudo-second-order kinetic equation.

KSC may be considered as a better adsorbent for removal of red RB and Yellow M4G dyes as compared to some other adsorbents. Belpatra removed red RB dye $94 \%$ [6], whereas activated carbon removed Yellow M4G dye only $84 \%$ [17].

\section{Conclusion}

Results have shown that KSC acts as an effective adsorbent for removal of torque blue, red RB and yellow M4G dyes from aqueous solutions. The overall experimental results suggested that KSC has the maximum adsorption for torque blue (98.9\%) followed by red RB (96.8\%) and yellow M4G (95.3\%) dyes. It was found that adsorption increased with increase in surface area of KSC. pH played an important role during adsorption. Percentage removal of red $\mathrm{RB}$ and yellow M4G dyes decreased with increase in $\mathrm{pH}$, whereas in the case of torque blue dye it increased with increase in $\mathrm{pH}$. The adsorption phenomenon was spontaneous, exothermic and favorable. Langmuir adsorption isotherm explained the monolayer coverage of adsorbates on KSC. The pseudo-second-order kinetics described the mechanism of adsorption.

\section{Compliance with ethical standards}

Conflict of interest The authors have no conflict of interest.

\section{References}

1. Katheresan V, Kansedo J, Lau SY (2018) Efficiency of various recent wastewater dye removal methods: a review. J Environ Chem Eng 6:4676-4697. https://doi.org/10.1016/j. jece.2018.06.060

SN Applied Sciences
2. Khan TA, Khan EA (2018) Adsorption of methyl red on activated carbon derived from custard apple (Annona squamosa) fruit shell: equilibrium isotherm and kinetic studies. J Mol Liq 249:1195-1211. https://doi.org/10.1016/j.molliq.2017.11.125

3. Singh NB, Nagpal G, Agrawal S, Rachna (2018) Water purification by using adsorbents: a review. J Environ Technol Innov 11:187-240. https://doi.org/10.1016/j.eti.2018.05.006

4. Zhou Y, Lu J, Zhou Y, Liu Y (2019) Recent advances for dyes removal using novel adsorbents: a review. Environ Pollut 252:352-365

5. Laura B, Belén EL, Solomon BO, Iqbal MN, Jan AK, Adegoke AF, Michael K, loannis A (2019) The utilization of leaf-based adsorbents for dyes removal: a review. J Mol Liq 276:728-747

6. Vandana G, Anupam A, Singh MK, Singh NB (2017) Removal of red RB dye from aqueous solution by belpatra bark charcoal (BBC) adsorbent. J Mater Environ Sci 8(10):3718-3729

7. Khan Tabrez A, Momina N (2015) Enhanced adsorptive removal of a model acid dye bromothymol blue from aqueous solution using magnetic chitosan-bamboo sawdust composite: batch and column studies. Environ Prog Sustain Energy 34(5):14441454. https://doi.org/10.1002/ep.12147

8. Okoli CA, Onukwuli OD, Okey-Onyesolu CF, Okoye CC (2015) Adsorptive removal of dyes from synthetic wastewater using activated carbon from tamarind seed. Eur Sci J 11:190-221

9. Mohammadi SZ, Karimi MA, Yazdy SN, Tayebeh S, Hooshang $\mathrm{H}$ (2014) Removal of $\mathrm{Pb}(\mathrm{II})$ ions and Malachite green dye from wastewater by activated carbon produced from lemon peel. Quim Nova 37:804-809. https://doi.org/10.5935/01004042.20140129

10. Nasuha N, Zurainan HZ, Maarof HI, Zubir NA, Amri N (2011) Effect of cationic and anionic dye adsorption from aqueous solution by using chemically modified papaya seed. In: international conference on environment science and engineering, pp 50-54

11. Kumar BS, Manjula B, Neelam R (2012) Sorptive removal of ciprofloxacin hydrochloride from simulated wastewater using sawdust: kinetic study and effect of $\mathrm{pH}$. Water SA 38(5):5. https ://doi.org/10.4314/wsa.v38i5.4

12. Al-azabi K, Al-marog S, Abukrain A, Sulyman M (2018) Equilibrium, isotherm studies of dye adsorption onto orange peel powder. Chem Res J 3:45-59

13. Khan TA, Khan EA (2016) Adsorptive uptake of basic dyes from aqueous solution by novel brown linseed deoiled cake activated carbon: Equilibrium isotherms and dynamics. J Environ Chem Eng 4:084-3095. https://doi.org/10.1016/j.jece.2016.06.009

14. Balasubramani K, Sivarajasekar N (2014) Adsorption studies of organic pollutants onto activated carbon. Int J Innov Res Sci Eng Technol 3:10575-10581

15. Silva LS, Lima LCB, Ferreira FJL, Silva MS, Osajima JA, Bezerra RDS, Silva Filho EC (2015) Sorption of the anionic reactive red RB dye in cellulose: assessment of kinetic, thermodynamic, and equilibrium data'. Open Chem 13:801-812. https://doi.org/10.1515/ chem-2015-0079

16. Chime CF, Achike DC (2018) Adsorptive removal of bromophenol blue dye from aqueous solution using acid activated clay. Int J Sci Res Manag 6:1-15

17. Abbas SH, Abood Waleed M (2014) Removal of reactive yellow dye by adsorption onto activated carbon using simulated wastewater. Desalin Water Treat 52:3421-3431. https://doi. org/10.1080/19443994.2013.800341

Publisher's Note Springer Nature remains neutral with regard to jurisdictional claims in published maps and institutional affiliations. 